\title{
A Profile of the Heat Generation Inside a Cigarette During Puffing*
}

\author{
by

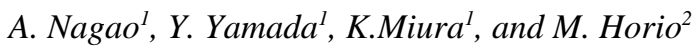 \\ ${ }^{1}$ Tobacco Science Research Center, Japan Tobacco Inc., Yokohama, Japan \\ ${ }^{2}$ Tokyo University of Agriculture and Technology, Tokyo, Japan
}

\section{SUMMARY}

The transient temperature distribution inside a burning cigarette during a 2 -second constant-draw single puff was measured to determine the heat generation rate at various positions. The calculation of the heat generation was applied only to a vertically positioned cigarette. The solidphase temperature was measured by an infrared thermometer with an optical fiber probe, and the gas-phase temperature was measured by a thermocouple. Heat generation rates at various positions inside the burning cigarette were obtained from the temperature distribution profile based on the heat balance equations. Heat generation was found to be concentrated within a region 2 to $3 \mathrm{~mm}$ behind the paper char line. The maximum heat generation rate was observed during the initial period of puffing and the heat generation rate decreased significantly in the interval during the middle unsteady period. Steady heat generation was observed in the latter period. The puffing volume as well as the properties of cigarette paper affected the heat generation rate during the unsteady period. The amount of the heat generated during the unsteady period was more than half of the total regardless of the cigarette paper basis weight and the puffing volume. [Beitr. Tabakforsch. Int. 21 (2005) 294-302]

\section{ZUSAMMENFASSUNG}

Die vorübergehende Temperaturverteilung in einer brennenden Zigarette während eines zwei Sekunden andauernden, konstanten Zuges wurde gemessen, um die Wärmeentwicklung an unterschiedlichen Positionen zu messen. Die Berechnung der Wärmeerzeugung wurde nur an vertikal ausgerichteten Zigaretten durchgeführt. Die Temperatur der Festphase wurde mit Hilfe eines Infrarot- thermometers mit einem Messfühler aus einer optischen Faser, die Temperatur der Gasphase mit Thermoelementen gemessen. Die Wärmeentwicklung an verschiedenen Positionen innerhalb der brennenden Zigarette ergab sich aus dem Temperaturverteilungs-Profil, das auf Berechnungen des thermischen Gleichgewichts beruht. Es wurde gefunden, dass sich die Wärmegenerierung 2 bis $3 \mathrm{~mm}$ hinter der Brennlinie des Papiers konzentrierte. Die maximale Wärmeentwicklung wurde zu Beginn eines Zuges beobachtet und nahm dann in der mittleren, instabilen Phase signifikant ab. Eine konstante Wärmeerzeugung wurde in der späteren Zugphase beobachtet. Sowohl das Zugvolumen als auch die Eigenschaften des Zigarettenpapiers hatten Einfluss auf die Wärmegenerierung während der instabilen Phase. Die Menge der während der instabilen Phase generierten Wärme machte mehr als die Hälfte der gesamten generierten Wärmemenge aus, unabhängig vom Gewicht des Papiers und dem Zugvolumen. [Beitr. Tabakforsch. Int. 21 (2005) 294-302]

\section{RESUME}

La distribution transitoire de la température à l'intérieur d'une cigarette en combustion au cours d'une bouffée constante de deux secondes a été mesurée pour déterminer le taux de génération de la chaleur en divers points. Le taux de génération de la chaleur a été calculé seulement pour les cigarettes positionnées verticalement. La température de la phase solide a été mesurée par thermomètre infrarouge avec détecteurs à fibres optiques, la phase gazeuse par thermocouple. Les taux de génération de la chaleur en divers points de la cigarette en combustion ont été obtenus à partir du profil de distribution de la température en se basant sur les équations d'équilibre thermique. Il a été observé que la génération de la chaleur s'est concentrée 


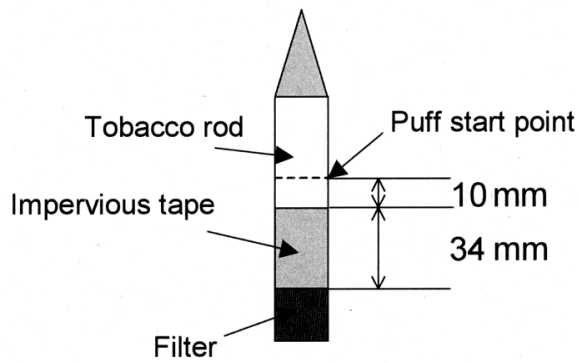

Figure 1. Cigarette setup for measurements

dans une région de 2 à $3 \mathrm{~mm}$ derrière la ligne de carbonisation. La génération maximale de la chaleur a été observée tout au début des bouffées et le taux de génération de la chaleur diminue significativement au cours de la période instable entre les bouffées. Une génération constante a été observée à la fin des bouffées. Le volume des bouffées et les propriétés du papier à cigarette affectent le taux de génération de la chaleur aux cours de la période instable. La quantité de la chaleur générée au cours de la période instable représente plus que la moitié de l'ensemble de la chaleur indépendamment du poids du papier à cigarette et du volume des bouffées. [Beitr. Tabakforsch. Int. 21 (2005) 294-302]

\section{INTRODUCTION}

The characteristics of mainstream smoke depend on the burn rate of the tobacco beds. Even though the details of the cigarette combustion have been investigated over decades, the heat generation rate inside a burning cigarette has not been calculated as a function of smoking regimes. BAKER $(1,2)$ reported the transient temperature and gas concentration profiles inside a cigarette during smoldering and puffing. He derived the important finding that the region of the maximum temperature and strong oxygen consumption is located behind the paper char line towards unburnt tobacco column. Many reports have presented data on the air flow field outside a burning cigarette during puffing $(1,3,4)$. These studies indicate that the air mainly enters from a region close to the paper char line. The results indicate that the air inflow near the paper char line causes the large burning rate of tobacco behind that region as mentioned above. On the other hand, YAMADA (5), PARRISH (6) and BAKER (7) measured the gas concentration profile of the mainstream smoke during puffing. They found that the generation rates of carbon monoxide, carbon dioxide, methane and the consumption rate of oxygen significantly change with time during puffing. This result points out that the heat generation rate of a burning cigarette should also change during puffing.

Many reports have been published concerning the effects of cigarette materials as well as puffing conditions on the amount of the mainstream smoke. LOUREAU (8) measured carbon monoxide concentration in the mainstream smoke for cigarette papers with different cigarette paper basis weights. He found that when the cigarette paper basis weight increased, the formation of carbon monoxide increased. BORGERDING et al. (9) measured 'tar', nicotine and other components in the mainstream smoke under the various puffing conditions and reported that the amount of these components increased with the puffing volume. BAKER (7) has summarized data on the temperature of the tobacco bed as a function of the volume of air calculated as entering the coal. He shows that the temperature on the surface of the cigarette coal increases as the volume of air drawn into the coal increases. Their work suggests that the burning rate should be changed markedly by the properties of the cigarette materials and the puffing volume. However, the transient behavior of the heat generation during puffing with the change of the cigarette materials and the puffing volume has not been clarified completely.

If we quantify the heat generation profiles for various cigarettes and puffing volumes, it should help us understand the transient changes of the burning rate of the tobacco bed at various positions during puffing. This paper focuses on the heat generation rate during puffing. The transient temperature distribution inside a burning cigarette during puffing was determined and the heat generation rates at various positions inside a burning cigarette were estimated. Also, in order to investigate the effect of the cigarette paper properties or the smoking regimes on the heat generation profile, the heat generation profile is discussed when the cigarette paper or the puffing volume are changed.

\section{EXPERIMENTAL}

\section{Measurement of temperature distribution inside a burning cigarette}

The cigarette setup for measuring the temperature distribution is shown in Figure 1. The inside of the filter section was empty. To eliminate flow entering through the nonburning cigarette paper, the part of the cigarette paper of $34 \mathrm{~mm}$ from the tobacco rod end was sealed with impervious tape. The temperature distributions of the solid and gas phases inside the burning cigarette during puffing were determined in two separate series of experiments. Figures $2 \mathrm{a}$ and $2 \mathrm{~b}$ show the experimental setups for measuring the solid phase temperature and gas-phase temperature, respectively. The setups for measuring were conducted by referring to BAKER's measurement method (1). The test cigarette was set vertically. The solid-phase temperature was measured using an infrared thermometer with an optical fiber probe of $0.8 \mathrm{~mm}$ in diameter (IR-FLONN04, CHINO Co.). The gas-phase temperature was measured using a bare thermocouple made from platinum/platinum-13\% rhodium ( $0.05 \mathrm{~mm}$ in diameter). Both the output voltage from the smoking machine (RGA-System R26, Borgwaldt Technik $\mathrm{GmbH}$ ) and the temperature data were logged at the same time using a data recorder (Omniace2, NEC Co.). The temperature was obtained at the intervals of $0.1 \mathrm{~s}$. After ignition, $15 \mathrm{~mm}$ of the cigarette was smoldered then it was puffed singly at a constant rate $(35 \mathrm{~mL}$ or $70 \mathrm{~mL}$ puff volume and 2-second puff duration) by a smoking machine. If the International Standard (ISO) puff profile is applied, the temperature profile will be dramatically changed as the amount of the air entering into the cigarette varies during the smoking regime. Therefore, to understand the transient change of the heat generation during puffing 
a)

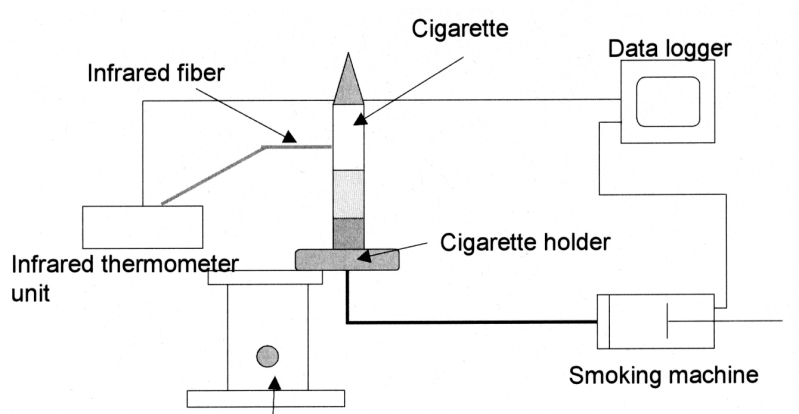

Mechanical stage

b)

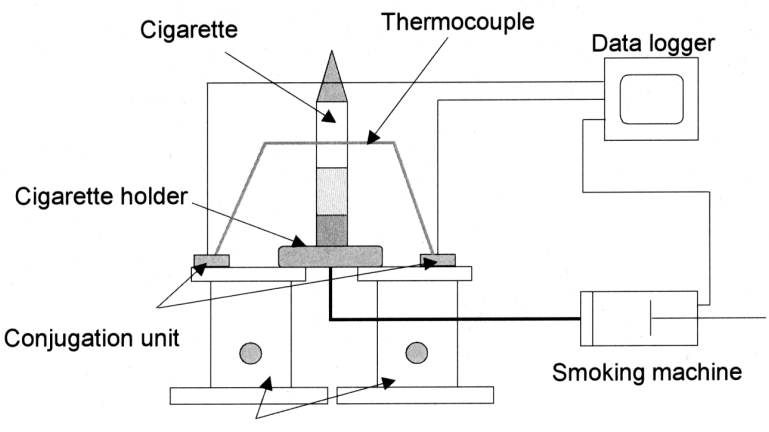

Mechanical stage

Figure 2. Experimental setups for measuring the gas-phase temperature (a) and the solid-phase temperature (b) of the burning cigarette during puffing

more easily, all measured cigarettes were puffed under the condition of the constant puffing rate. Figure 3 shows the locations for measuring the temperature inside a burning cigarette. One temperature measurement was taken in one point of a single cigarette. All measurements were conducted in a room where the temperature and relative humidity were controlled at $22{ }^{\circ} \mathrm{C}$ and $60 \%$, respectively. The design specifications of the two cigarettes tested are shown in Table 1. The basis weight of the cigarette paper, which is one of the effective properties on the burning rate of cigarettes (8), was different in these two samples and there was also a small difference in the amount of the burn additive, which consisted of potassium citrate. The same paper density was used but the paper thickness of cigarettes $\mathrm{A}$ and $\mathrm{B}$ was different. The sample cigarettes were 8 $\mathrm{mm}$ in diameter and $0.23 \mathrm{~g} / \mathrm{cm}^{3}$ in tobacco density. The cigarettes were made of the same tobacco blend, which is American blend tobacco.

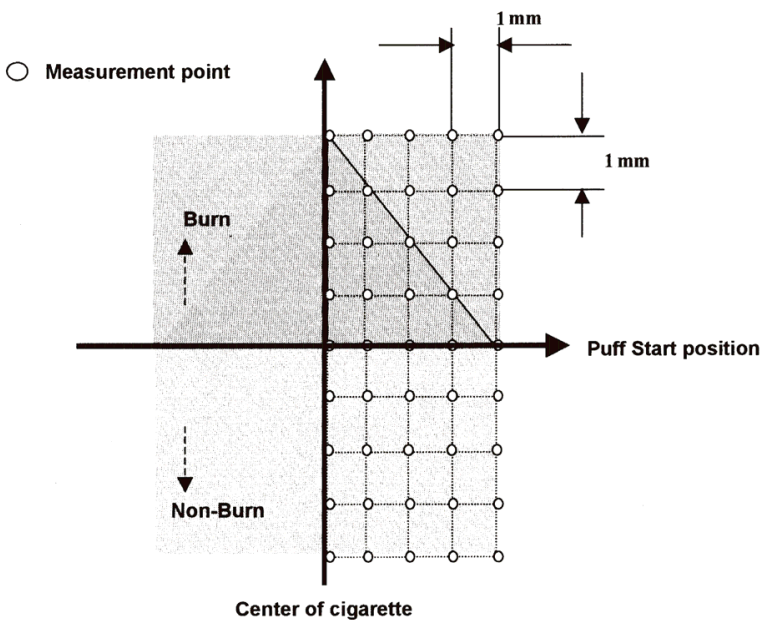

Figure 3. The temperature measurement positions inside the burning cigarette

\section{Calculation of heat generation rate at various positions inside the burning cigarette}

Heat generation rate inside the cigarette during puffing can be determined from the temperature profile using the following heat balance equation;

$$
\begin{aligned}
\frac{\partial Q}{\partial t}= & C_{p} \rho(1-\phi) \frac{\partial T_{\mathrm{s}}}{\partial t}-\lambda \nabla T_{\mathrm{s}}-h S\left(T_{\mathrm{g}}-T_{\mathrm{s}}\right) \\
& -\varepsilon \sigma(1-\phi) S \operatorname{Ra}\left(T_{\mathrm{s}}\right)
\end{aligned}
$$

where $T_{\mathrm{s}}$ is the solid phase temperature, $T_{\mathrm{g}}$ is the gas-phase temperature, $Q$ is the heat generated, $t$ is the time during puffing, $h$ is the convective heat transfer term as the air flow velocity inside the burning cigarette, $C_{p} \rho$ is the heat capacity, $\lambda$ is the thermal conductivity of the tobacco bed, $\varepsilon$ is the emissivity, $\sigma$ is the Stefan-Boltzmann constant, $S$ is the tobacco surface area per volume and $\phi$ is the space ratio. $\mathrm{Ra}$ is a radiation term function as the temperature of the solid phase. They were introduced to make the notation simpler.

To obtain the heat generation rate $\partial q_{i j}^{t} / \partial t$ at each position $i$ and $j$ inside the burning cigarette at time $t$, expressions for solid phase temperature $T_{\mathrm{s} i j}^{t}$ and gas-phase temperature $T_{\mathrm{g} i j}^{t}$, where $i=1$ to $4, j=1$ to 4 and -1 to -4 , are introduced, breaking down the above differential equation into a simple equation. Then each term in Eqn. [1] is approximated respectively by

Table 1. Cigarette samples

\begin{tabular}{l|cc|c|c|c|c}
\hline \multirow{2}{*}{ Samples } & \multicolumn{2}{|c|}{ Tobacco rod properties } & \multicolumn{4}{c}{ Cigarette paper properties } \\
\cline { 2 - 7 } & Diameter, $\mathrm{mm}$ & Density, $\mathrm{g} / \mathrm{cm}^{3}$ & Basis weight, $\mathrm{g} / \mathrm{m}^{2}$ & Filler, \% & Potassium citrate, \% & Permeability, CU $^{\text {a }}$ \\
\hline Cigarette A & 8 & 0.23 & 23 & 40 & 0.9 & 35 \\
Cigarette B & 8 & 0.23 & 40 & 40 & 0 & 35 \\
\hline
\end{tabular}

${ }^{\mathrm{a}} \mathrm{CU}=$ CORESTA unit, $\mathrm{cm} \mathrm{min}^{-1} \mathrm{kPa}^{-1}$. 


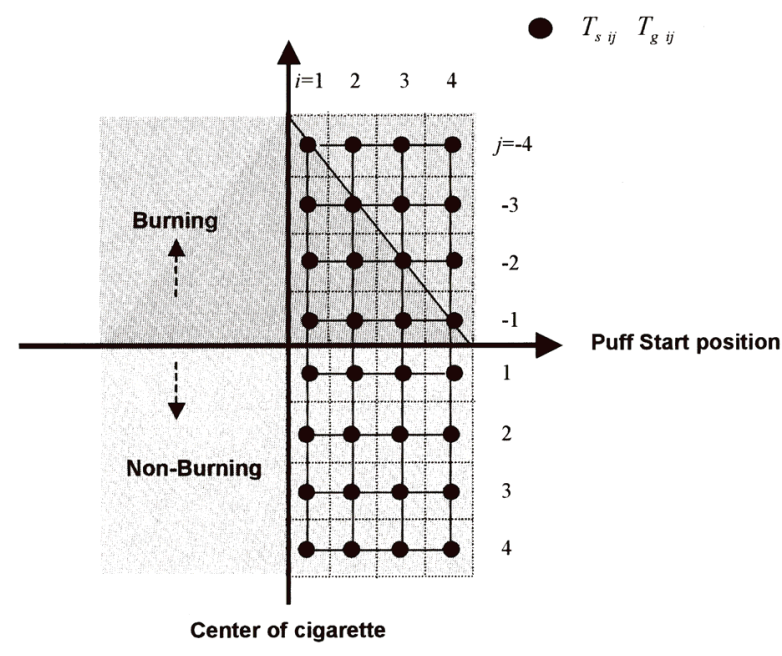

Figure 4. The positions of $T_{\mathrm{s} i j}$ and $T_{\mathrm{g} i j}$ inside a burning cigarette as the dotted points

$$
\begin{gathered}
C_{p} \rho(1-\phi) \frac{\partial T_{\mathrm{s} i j}^{t}}{\partial t}=C_{p} \rho(1-\phi)\left(T_{\mathrm{s} i j}^{t}-T_{\mathrm{s}}^{t-1}\right) \\
\lambda \nabla T_{\mathrm{s} i j}^{t}=\lambda \frac{\left(T_{\mathrm{s} i+1 j}^{t}-2 T_{\mathrm{s} i j}^{t}+T_{\mathrm{s} i-1 j}^{t}\right)}{\partial r} \\
+\lambda \frac{\left(T_{\mathrm{s} i j+1}^{t}-2 T_{\mathrm{s} i j}^{t}+T_{\mathrm{s} i j+1}^{t}\right)}{\partial z} \\
h\left(T_{\mathrm{g} i j}^{t}-T_{\mathrm{s} i j}^{t}\right)=h\left(v_{i j}\right)\left(T_{\mathrm{g} i j}^{t}-T_{\mathrm{s} i j}^{t}\right) \\
\operatorname{Ra}\left(T_{\mathrm{s} i j}^{t}\right)=\left(\frac{T_{\mathrm{s} i+1 j}^{t}}{100}\right)^{4}-2\left(\frac{T_{\mathrm{s} i j}^{t}}{100}\right)^{4}+\left(\frac{T_{\mathrm{s} i-1 j}^{t}}{100}\right)^{4} \\
+\left(\frac{T_{\mathrm{s} i j+1}^{t}}{100}\right)^{4}-2\left(\frac{T_{\mathrm{s} i j}^{t}}{100}\right)^{4}+\left(\frac{T_{\mathrm{s} i j-1}^{t}}{100}\right)^{4}
\end{gathered}
$$

where $t=0.1$ to 2 is the time during puffing, $i=1$ to 4 is the position in the radial direction, $j=1$ to 4 and -1 to -4 is the position in the axial direction, $T_{\mathrm{s} i j}$ is the solid-phase temperature at position $i$ and $j, T_{\mathrm{g} i j}$ is the gas temperature at position $i$ and $j$ shown in Figure 4 . The symbol $v_{i j}$ in Eqn. [2.3] shows the flow velocity at position $i$ and $j, h$ is the convective coefficient given by SANDUSKY et al. (10), $r$ and $z$ shows the radial direction and axial direction, respectively. Figure 4 shows the positions of $T_{\mathrm{s} i j}$ and $T_{\mathrm{g} i j}$ inside a burning cigarette as the dotted points. $T_{\mathrm{s} i j}$ and $T_{\mathrm{g} i j}$ is obtained from the experimental measurements.

The term $\partial q_{i j}^{t} / \partial t$ can be obtained by the following equation:

$$
\begin{aligned}
\frac{\partial q_{i j}^{t}}{\partial t}= & C_{p} \rho(1-\phi) \frac{\partial T_{\mathrm{s} i j}^{t}}{\partial t}-\lambda \nabla T_{\mathrm{s} i j}^{t}-h S\left(T_{\mathrm{g} i j}^{t}-T_{\mathrm{s} i j}^{t}\right) \\
& -\sigma \varepsilon(1-\phi) S \operatorname{Ra}\left(T_{\mathrm{s} i j}^{t}\right)
\end{aligned}
$$

Total heat generation rate at time $t$ inside the burning ciga rette during puffing can be obtained by summarizing $\partial q_{i j}^{t} / \partial t$ for $i$ and $j$ as follows:
Table 2. The properties in the heat balance equations ( $v$ in $h$ shows the velocity at each position inside the burning cigarette)

\begin{tabular}{lccl}
\hline \multicolumn{2}{l}{ Symbol [unit] } & Value & Property \\
\hline$\lambda$ & {$[\mathrm{W} / \mathrm{m} / \mathrm{K}]$} & $1.7 \times 10^{-2}$ & Thermal conductivity \\
$C_{\rho} \rho$ & {$\left[\mathrm{J} / \mathrm{m}^{3} / \mathrm{K}\right]$} & $1.6 \times 10^{6}$ & Heat capacity \\
$h$ & {$\left[\mathrm{~W} / \mathrm{m}^{2} / \mathrm{K}\right]$} & $3.6 \times 10^{-1} v$ & $\begin{array}{l}\text { Convective heat coefficient } \\
\text { by Sandusky et al. (10) }\end{array}$ \\
$\epsilon$ & {$[-]$} & $9.0 \times 10^{-1}$ & $\begin{array}{l}\text { Emissivity } \\
\phi\end{array}$ \\
$S$ & {$[\%]$} & 66 & Space ratio \\
& {$\left[\mathrm{m}^{2} / \mathrm{m}^{3}\right]$} & $3.9 \times 10^{-2}$ & Tobacco surface area \\
\hline
\end{tabular}

$$
\frac{\partial Q_{\mathrm{t}}}{\partial t}=\sum_{i, j}\left(\int_{i-1}^{i} d r \frac{\partial q_{i j}^{t}}{\partial t} \frac{\pi r}{4}\right)
$$

Table 2 shows the properties used in the equations. The convective heat transfer coefficient $h$ is referred to in SANDUSKY et al. (10). Since the heat transfer coefficient $h$ is dependent on the flow velocity, the flow velocity distribution inside the cigarette during puffing was calculated using Finite Dimensional Analysis Code, Fluent UNF (FLUENT Co. Ltd.). This calculation was conducted using the continuity equation, the motion equation, the mass conservation equation and the ideal gas equation:

$$
\begin{gathered}
\frac{\partial v_{x}}{\partial x}+\frac{\partial v_{y}}{\partial y}=0 \\
\rho_{\mathrm{g}}\left(\frac{\partial\left(v_{x}+v_{y}\right)}{\partial t}\right)+v_{x}\left(\frac{\partial v_{x}}{\partial x}+\frac{\partial v_{y}}{\partial x}\right)+v_{y}\left(\frac{\partial v_{x}}{\partial y}+\frac{\partial v_{y}}{\partial y}\right) \\
=-\left(\frac{\partial P}{\partial x}+\frac{\partial P}{\partial y}\right)+\mu\left(\Delta v_{x}+\Delta v_{y}\right)+\rho_{\mathrm{g}} g_{y} \\
\frac{\partial \rho_{\mathrm{g} k}}{\partial t}=\frac{1}{\partial x}\left(-\rho_{\mathrm{g}} D \frac{\partial m_{k}}{\partial x}\right)+\frac{1}{\partial y}\left(-\rho_{\mathrm{g}} D \frac{\partial m_{k}}{\partial y}\right)+G_{k} \\
P=\frac{R T_{g}}{\sum_{k} m_{k}}
\end{gathered}
$$

where $v_{x}$ and $v_{y}$ are the flow rate in radial and axial directions, respectively, $\rho_{g}$ is the fluid density, $\mu$ is the fluid viscosity, $g_{y}$ is the acceleration of the gravity, $\rho_{g k}$ is the fluid density of specie $i, D$ is the fluid diffusion coefficient which is obtained from $6.2 \times 10^{-8} T_{\mathrm{g}} 1.83, m_{i}$ is the mass fraction of specie $k, G_{k}$ is the rate of chemical species generation and $R$ is the gas constant. Species $k$ show $\mathrm{CO}, \mathrm{CO}_{2}$, $\mathrm{O}_{2}$ and $\mathrm{N}_{2} \cdot \mathrm{G}_{\mathrm{N} 2}$ is equal to 0 .

The second term in the right side of the Eqn. [6] is obtained from the DARCY equation:

$$
\frac{\partial P}{\partial x}=\frac{\mu v_{x}}{C}, \frac{\partial P}{\partial y}=\frac{\mu v_{y}}{C}
$$

where $C$ is the free permeability of the cigarette paper and tobacco bed. 


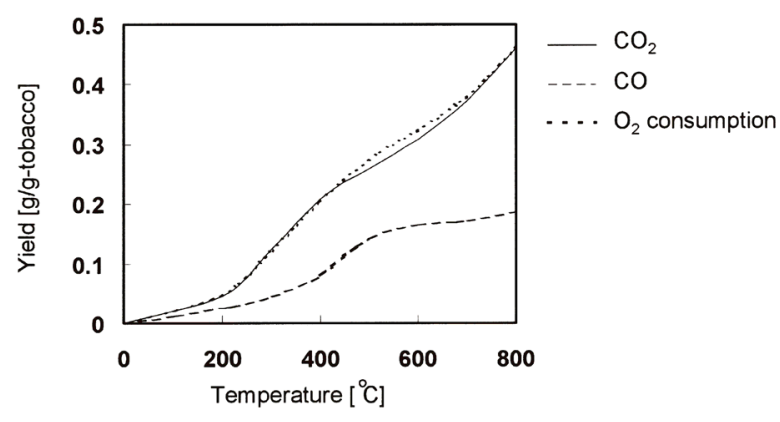

Figure 5. Yield of carbon dioxide, carbon monoxide and oxygen consumption as the function of the temperature
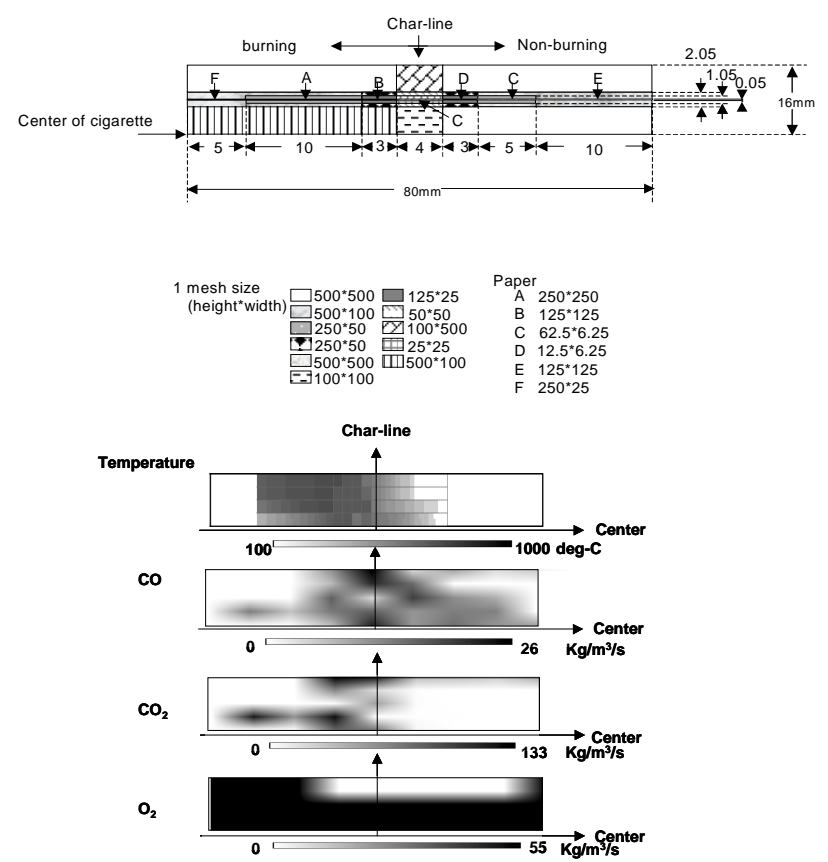

Figure 6. Mesh used for the calculation of the flow distribution and the temperature, gas concentration distribution for calculation

To simplify the calculation, it was carried out using the experimental temperature at $1 \mathrm{~s}$ during puffing obtained in this work, and the distributions of the rate of the chemical species generation for $\mathrm{CO}, \mathrm{CO}_{2}$ and $\mathrm{O}_{2}$ at $1 \mathrm{~s}$ during puffing. The rates of the chemical species at each location inside the burning cigarette at $1 \mathrm{~s}$ were obtained from the temperature distribution at 0.9 and $1 \mathrm{~s}$ and the profile of the chemical species generation as the function of the temperature, shown in Figure 5. The method for measuring the profile of the chemical species generation is shown by TORIKAI et al. (12). Figure 6 shows the calculation mesh, the temperature and distributions of the rate of the chemical species generation for $\mathrm{CO}, \mathrm{CO}_{2}$ and $\mathrm{O}_{2}$. It was assumed that the cigarette has the rotational symmetry of the center axial. The values of $C$ were used as $5.6 \times 10^{-15}$ for the cigarette paper and $8.3 \times 10^{-10}$ for the other regions. Fluid viscosity $\mu$ is shown in Table 3 . Figure 7 shows the flow velocity distribution obtained from the calculation under two different flow rates of 35 and $70 \mathrm{~mL} / 2 \mathrm{~s}$.
Table 3. Fluid viscosity for calculation

\begin{tabular}{lll}
\hline Parameters & Temperature $[\mathrm{K}]$ & Viscosity $\left[\mathrm{kg} / \mathrm{m}^{3} / \mathrm{s}\right]$ \\
\hline $\mathrm{N}_{2}$ & $T<373$ & $(\mathrm{~T}-273) \times 4.6 \times 10^{-8}+1.7 \times 10^{-5}$ \\
& $373 \leq T<473$ & $(\mathrm{~T}-373) \times 3.5 \times 10^{-8}+2.1 \times 10^{-5}$ \\
& $473 \leq T<573$ & $(\mathrm{~T}-473) \times 3.2 \times 10^{-8}+2.5 \times 10^{-5}$ \\
& $573 \leq T<673$ & $(\mathrm{~T}-573) \times 3.6 \times 10^{-8}+2.8 \times 10^{-5}$ \\
& $T>673$ & $(\mathrm{~T}-273) \times 3.3 \times 10^{-8}+3.2 \times 10^{-5}$ \\
$\mathrm{O}_{2}$ & $T<373$ & $(\mathrm{~T}-273) \times 5.0 \times 10^{-8}+2.0 \times 10^{-5}$ \\
& $373 \leq T<473$ & $(\mathrm{~T}-373) \times 4.5 \times 10^{-8}+2.5 \times 10^{-5}$ \\
& $473 \leq T<573$ & $(\mathrm{~T}-473) \times 4.5 \times 10^{-8}+2.9 \times 10^{-5}$ \\
& $573 \leq T<673$ & $(\mathrm{~T}-573) \times 4.0 \times 10^{-8}+3.3 \times 10^{-5}$ \\
& $T>673$ & $(\mathrm{~T}-273) \times 3.5 \times 10^{-8}+3.8 \times 10^{-5}$ \\
$\mathrm{CO}$ & $T<373$ & $(\mathrm{~T}-273) \times 4.6 \times 10^{-8}+1.7 \times 10^{-5}$ \\
& $373 \leq T<473$ & $(\mathrm{~T}-373) \times 3.5 \times 10^{-8}+2.1 \times 10^{-5}$ \\
& $473 \leq T<573$ & $(\mathrm{~T}-473) \times 3.2 \times 10^{-8}+2.5 \times 10^{-5}$ \\
& $573 \leq T<673$ & $(\mathrm{~T}-573) \times 3.6 \times 10^{-8}+2.8 \times 10^{-5}$ \\
& $T>673$ & $(\mathrm{~T}-273) \times 3.3 \times 10^{-8}+3.2 \times 10^{-5}$ \\
$\mathrm{CO}_{2}$ & $T<373$ & $(\mathrm{~T}-273) \times 4.0 \times 10^{-8}+1.4 \times 10^{-5}$ \\
& $373 \leq T<473$ & $(\mathrm{~T}-373) \times 5.0 \times 10^{-8}+1.8 \times 10^{-5}$ \\
& $473 \leq T<573$ & $(\mathrm{~T}-473) \times 3.0 \times 10^{-8}+2.3 \times 10^{-5}$ \\
& $573 \leq T<673$ & $(\mathrm{~T}-573) \times 3.5 \times 10^{-8}+2.5 \times 10^{-5}$ \\
& $T>673$ & $(\mathrm{~T}-273) \times 4.0 \times 10^{-8}+3.0 \times 10^{-5}$ \\
\hline
\end{tabular}
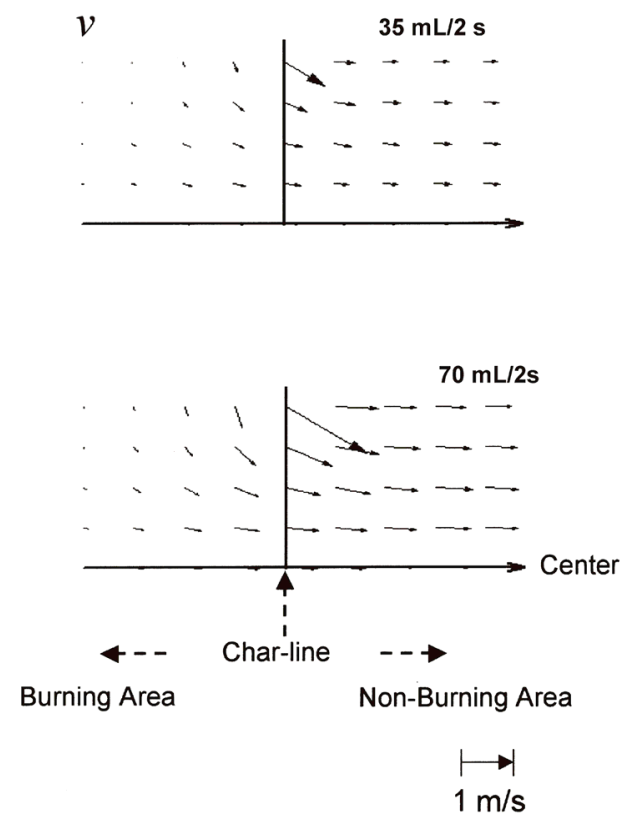

Figure 7. Flow velocity distribution inside the burning cigarette

\section{RESULTS AND DISCUSSION}

\section{Identification of the heat generation region inside the cigarette}

Figure 8 shows the estimated heat generation rate inside the burning cigarette. In spite of the constant puffing rate, the heat generation rate was not invariable during puffing. The heat generation profile was roughly classified into two periods. The heat generation rate was increased from 0 to $0.3 \mathrm{~s}$ after the puff-start and from 0.3 to $0.9 \mathrm{~s}$ the heat genera- 


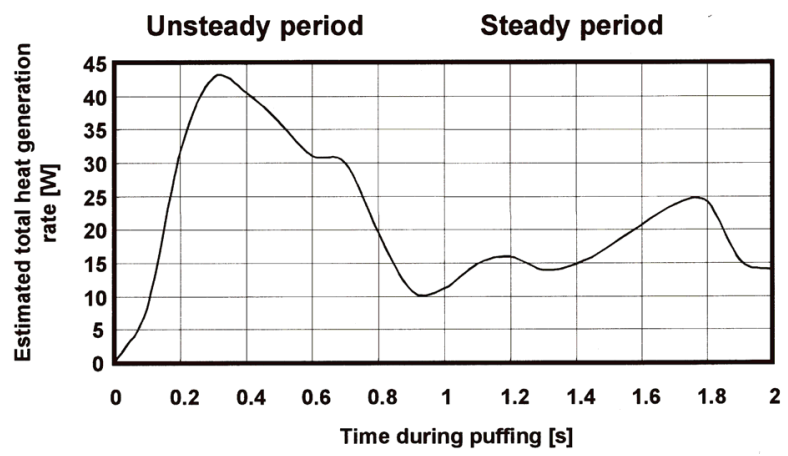

Figure 8. Estimated total heat generation rate during puffing for cigarette $A$ under $35 \mathrm{~mL} / 2 \mathrm{~s}$ puffing condition

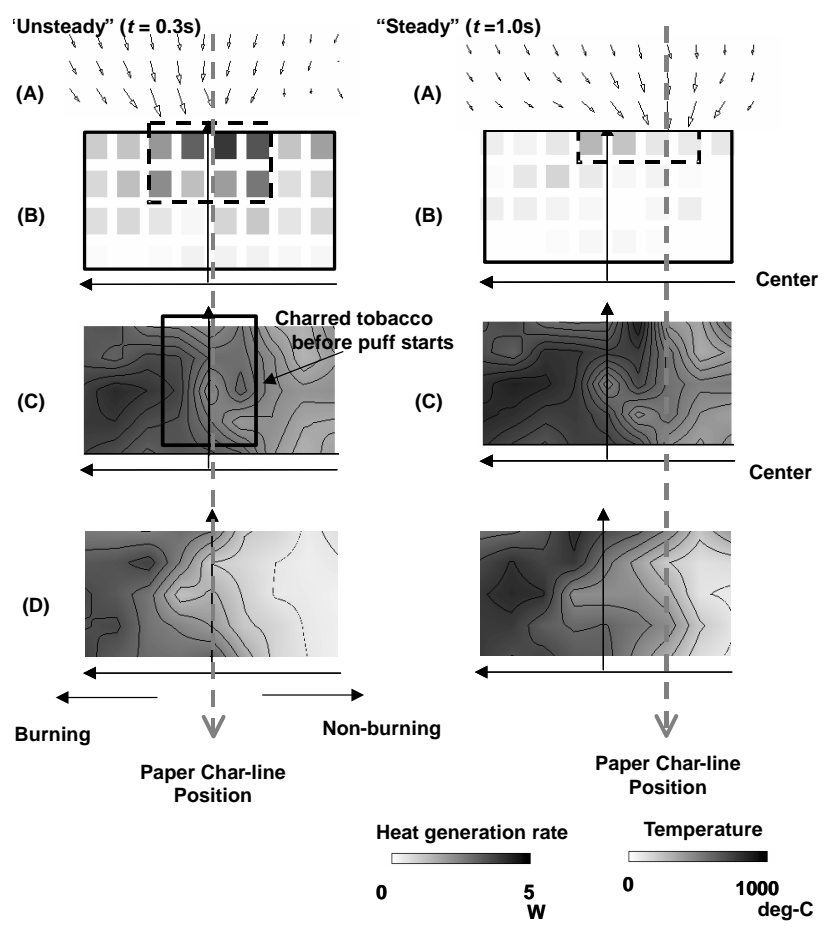

Figure 9. The transient change of cigarette burning during a puff for the unsteady and steady periods at $35 \mathrm{~mL} / 2 \mathrm{~s}$. (A) The flow distributions outside the cigarette (3); (B) The heat generation rate; $(C)$ The solid-phase temperature distributions inside the cigarette; (D) The gas-phase temperature distributions inside the cigarette.

tion was observed from 0.9 to $2.0 \mathrm{~s}$ (i.e. steady period). The total heat generated during puffing was approximately 44 Joule. YАМАМОTO et al. (13) have reported that the weight loss of the burning cigarette during puffing is approximately 20 to $30 \mathrm{mg}$. Therefore, if it is assumed that the weight loss of the cigarette in this study is from 20 to 30 $\mathrm{mg}$ during puffing, the heat output during puffing may be from 1.5 to $2.2 \mathrm{~J} / \mathrm{mg}$ tobacco. On the other hand, WAYMACK et al. (14) and MIURA et al. (15) show that the heat output from smoldering cigarettes is approximately 7.6 $\mathrm{J} / \mathrm{mg}$ tobacco. Even though the calculation for the heat generation rate is not exact or the repeatability of measuring the temperature is poor, the heat output obtained from puffing cigarettes is much smaller than from smoldering cigarettes. This may be because the ratio of weight loss of the pyrolyzed tobacco to the oxidation tobacco during

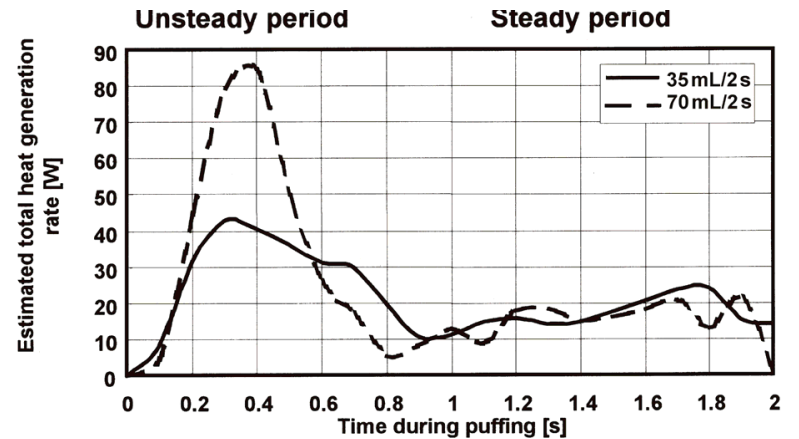

Figure 10. Estimated total heat generation rate during puffing for 35 and $70 \mathrm{~mL} / 2 \mathrm{~s}$ puffing volumes

puffing is higher than during smoldering, or there may be a significant difference in the combustion reaction pathway between puffing and smoldering. However, the reason has not been clarified.

Figure 9 shows the experimental flow rate distributions outside the cigarette (3), the estimated heat generation rate distributions, the solid- and gas-phase temperature distributions inside the cigarette at $t=0.3 \mathrm{~s}$ (the unsteady period) and at $t=1.0 \mathrm{~s}$ (the steady period) under a $35 \mathrm{~mL} / 2 \mathrm{~s}$ puff. The dotted arrows show the paper char-line positions at each period. The dotted lattices show the main region of the heat generation. There was a difference of the temperature near the paper char-line between the gas and solid phase because the air entered through the paper char-line. This agrees with BAKER's results (1). The high temperature region was not equivalent to the high heat generation rate region. The heat generation took place mainly at the region close to the paper char-line in each period and moved in conjunction with the paper char-line. In particular, there was a significant heat generation at $2 \mathrm{~mm}$ around the paper char-line during the unsteady period. The region behind the paper char-line exhibited a temperature from 300 to $500{ }^{\circ} \mathrm{C}$ at the start of the puff (1). This means that this temperature is close to or above the ignition temperature of the tobacco. Therefore, it is inferred that the significant heat generation occurred during the unsteady period because most of the air enters the region close to the paper char-line and the tobacco has a relatively higher temperature than the tobacco in the same region within the steady period, and the tobacco near this region is oxidized more intensively to release the heat. In this study, the constant puffing rate is applied. Even though the ISO standard smoking regimen is not applied, the heat generation profile may not be similar to the profile of the air entering into the cigarette because more heat generation will occur in the initial time as the air enters into the pyrolized tobacco bed with the high temperature near the paper in that time.

\section{Effect of puffing volume on the cigarette combustion}

The effect of the puffing volume on the cigarette combustion was investigated. Figure 10 shows the estimated heat generation rate inside a burning cigarette for 35 and 70 $\mathrm{mL} / 2 \mathrm{~s}$. The heat generation profile for $70 \mathrm{~mL} / 2 \mathrm{~s}$ can also be roughly classified into two periods equivalent to those for $35 \mathrm{~mL} / 2 \mathrm{~s}$. A significant increase in the heat generation rate was observed with the puffing volume during the 


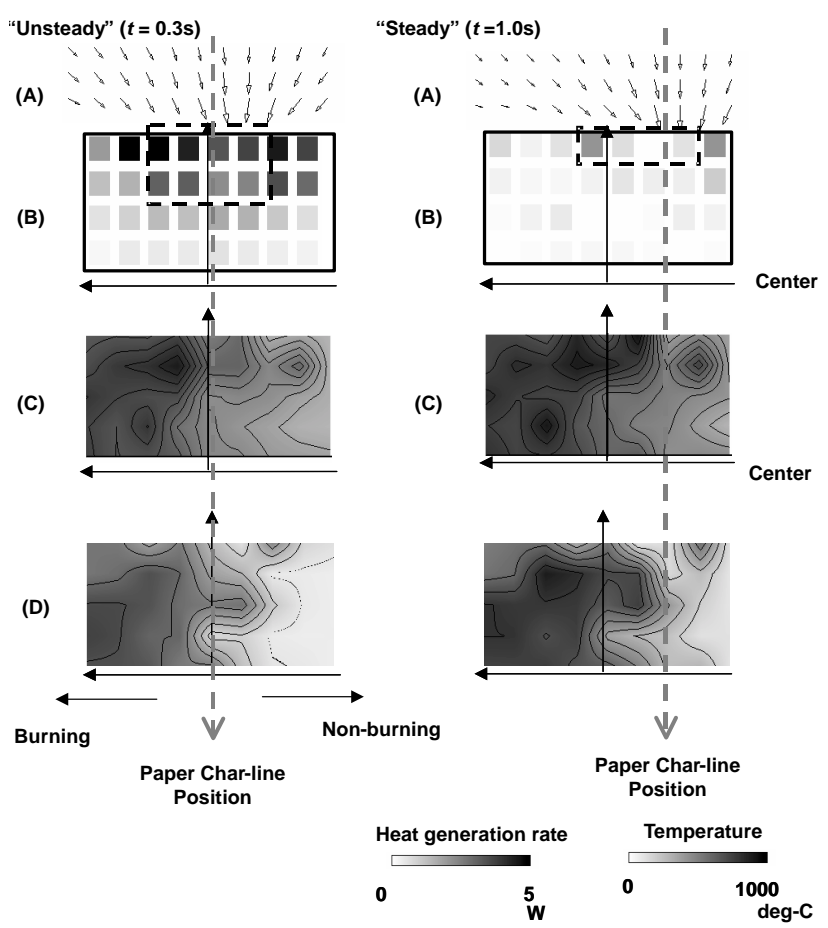

Figure 11. The transient change of cigarette burning during a puff for the unsteady and steady periods at $70 \mathrm{~mL} / 2 \mathrm{~s}$. (A) The flow distributions outside the cigarette (3); (B) The heat generation rate (C); The solid temperature distribution inside the cigarette; (D) The gas-phase temperature distributions inside the cigarette.

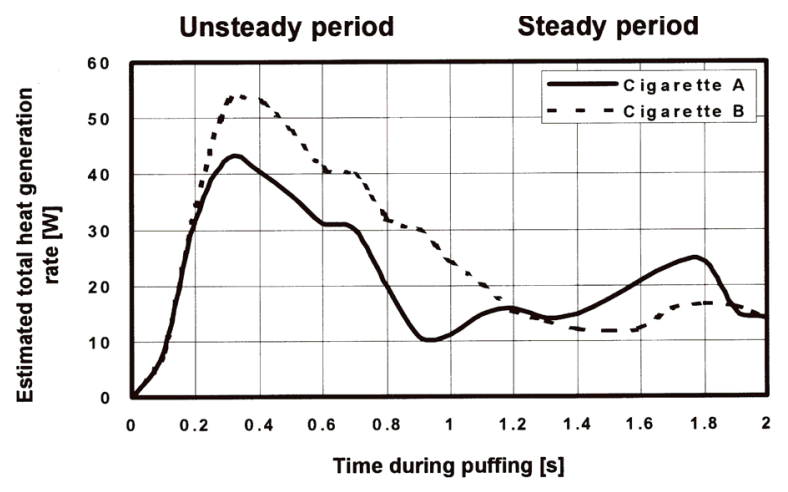

Figure 12. Estimated total heat generation rate during puffing cigarettes $A$ and $B$ under $35 \mathrm{~mL} / 2 \mathrm{~s}$ puffing condition

unsteady period. During the steady period, the puffing volume did not affect the heat generation rate. Figure 11 shows the flow rate distributions outside the cigarette, the estimated heat generation rate distributions, the solid- and gas-phase temperature distributions for the $70 \mathrm{~mL} / 2 \mathrm{~s}$ puff. The difference for the $70 \mathrm{~mL} / 2 \mathrm{~s}$ puff in the temperature near the paper char-line between the solid- and gas-phase was larger than that for the $35 \mathrm{~mL} / 2 \mathrm{~s}$. This should be due to the increase of the flow velocity entering through the paper char-line. The region with heat generation for 70 $\mathrm{mL} / 2 \mathrm{~s}$ during the unsteady period was larger than for 35 $\mathrm{mL} / 2 \mathrm{~s}$, and the heat generation rate behind the paper charline for $70 \mathrm{~mL} / 2 \mathrm{~s}$ increased compared with $35 \mathrm{~mL} / 2 \mathrm{~s}$. This may be caused by the increased air supply through the paper char-line with the $70 \mathrm{~mL} / 2 \mathrm{~s}$ puff (Figure 7).
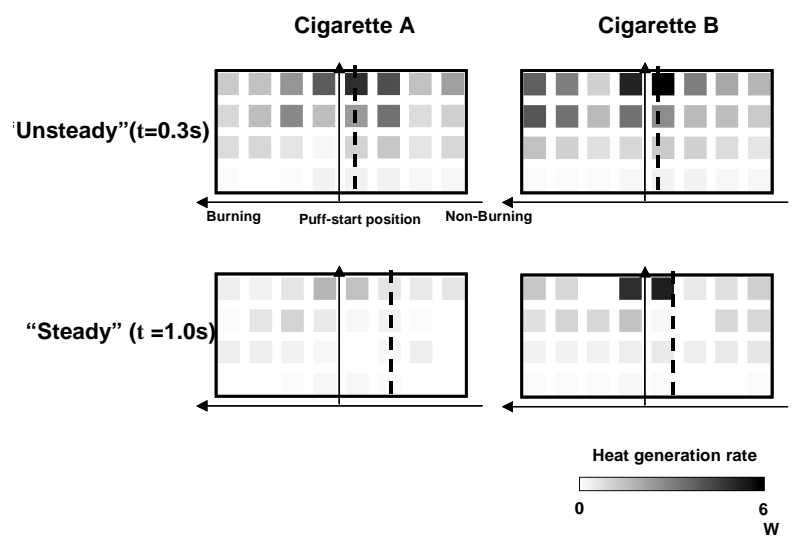

Figure 13. The heat generation rate distributions inside the cigarette during the unsteady and steady periods for cigarettes $A$ and $B$ under $35 \mathrm{~mL} / 2$ s puffing volume

\section{Effect of cigarette paper on the cigarette combustion}

The effects of cigarette paper designs on the heat generation rate were also investigated. Figure 12 shows the estimated heat generation rate inside the burning cigarette for cigarettes A and B. The cigarette paper basis weight was different between the two samples, and there was also a small difference in the burn additive contents. The heat generation rate for cigarette $\mathrm{B}$ was larger than cigarette $\mathrm{A}$ during the unsteady period. However, there was no significant difference in the heat generation rate between cigarettes during the steady period. Figure 13 shows the heat generation rate distribution inside the cigarette at $t=0.3 \mathrm{~s}$ (the unsteady period) and at $t=1.0 \mathrm{~s}$ (the steady period) for cigarettes $\mathrm{A}$ and $\mathrm{B}$. The heat generation rate behind the paper char-line for cigarette B slightly increased compared to cigarette A. Since the air is always flowing into the region close to the paper char-line during puffing regardless of cigarette paper basis weight applied in this study (4), the position of the air inflow into the burning cigarette should be determined by the burn rate of the cigarette paper during puffing. Accordingly, if the burn rate of the cigarette paper increases, it is assumed that the amount of air supply into the high temperature tobacco bed behind the paper char-line should decrease. In fact, the burn propagation distance of the cigarette paper $2.9 \mathrm{~mm} /$ puff for cigarette A was larger than the $2.3 \mathrm{~mm} /$ puff for cigarette $\mathrm{B}$. The authors of this work (16) show that the burn rate of the cigarette paper increases as the cigarette paper basis weight decreases. This may cause the difference in the heat generation rate in the unsteady period between cigarettes $\mathrm{A}$ and $\mathrm{B}$.

\section{Ratio of the cumulative heat generation at each interval to total heat generation during puffing}

Figure 14 shows the ratio of the cumulative amount of heat generated relative to the total heat during puffing. More than half of the total heat during puffing was generated during the steady period irrespective of the change in the cigarette paper and the puffing volume. This result indicates that the heat generation behind paper char-line during the unsteady period affects the total heat generation during puffing. 


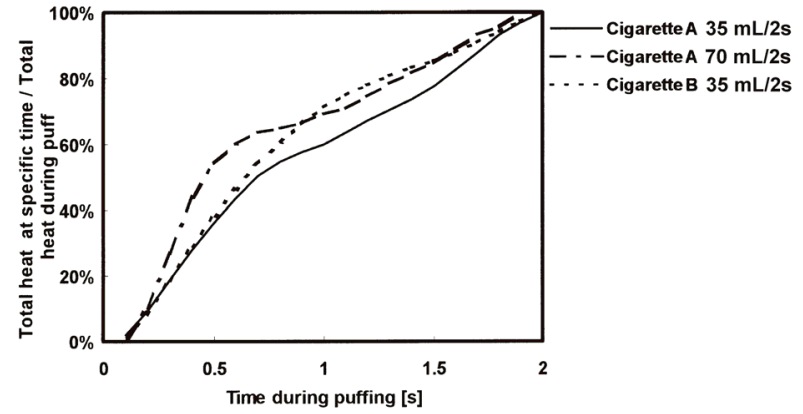

Figure 14. Ratio of the cumulative amount of heat generated relative to the total heat during puffing

\section{CONCLUSIONS}

We focused on the heat generation rate distribution during puffing. The transient change of the temperature distribution inside a burning cigarette during puffing was determined and the net heat generation rates at various positions inside a burning cigarette were estimated. The heat generation profiles with different cigarette papers and two puffing volumes were evaluated.

In spite of the constant puffing rate, the heat generation rate was not invariable during puffing. The heat generation profile was roughly classified into two periods. The heat generation rate increased in the initial period during puffing and then decreased significantly (the unsteady period), and stable heat generation was observed in the later period during puffing (steady period). The heat generation took place mainly in the region close to the paper char-line during each period and followed the movement of the paper char line. In particular, there was significant heat generation around the paper char-line during the unsteady period. When the puffing rate and cigarette basis weight increased, the heat generation rate during the unsteady period increased at the region behind paper char-line. More than half of the total heat produced during puffing was generated during the unsteady period.

\section{NOMENCLATURE}

$C_{p}=$ Specific heat $(\mathrm{J} / \mathrm{kg} / \mathrm{K})$

$D=$ Diffusion coefficient $\left(\mathrm{m}^{2} / \mathrm{s}\right)$

$g_{y}=$ Acceleration of gravity $\left(\mathrm{m} / \mathrm{s}^{2}\right)$

$G=$ Rate of specie generation $\left(\mathrm{kg} / \mathrm{m}^{3} / \mathrm{s}\right)$

$h=$ Convective heat coefficient $\left(\mathrm{J} / \mathrm{m}^{3} / \mathrm{K}\right)$

$\mathrm{m}=$ Mass fraction $(-)$

$P=$ Pressure $(\mathrm{Pa})$

$Q=$ Heat generated $(\mathrm{J})$

$r=$ Radial coordinate $(\mathrm{m})$

$R=$ Gas constant $(\mathrm{J} / \mathrm{K} / \mathrm{mol})$

$\mathrm{Ra}=$ Radiation heat term $\left(\mathrm{J} / \mathrm{s} / \mathrm{m}^{3}\right)$

$S=$ Tobacco surface area per volume $(1 / \mathrm{m})$

$t=$ Time during puffing $(\mathrm{s})$

$T=$ Temperature $(\mathrm{K})$

$v=$ Velocity for fluid in cigarette $(\mathrm{m} / \mathrm{s})$

$z=$ Axial coordinate $(\mathrm{m})$

$\varepsilon=$ Emissivity $(-)$

$\lambda=$ Thermal conductivity $(\mathrm{J} / \mathrm{s} / \mathrm{K})$

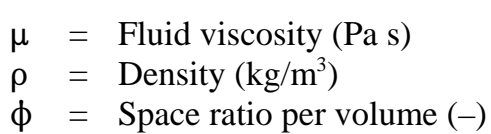

\section{Subscripts}

$g=$ Gas phase

$i=$ Position for radial direction

$j=$ Position for axial direction

$k=$ Species

$s \quad=$ Solid phase

\section{REFERENCES}

1. Baker, R.R.: Temperature variation within a cigarette combustion coal during the smoking cycle; High Temp. Sci. 7 (1975) 236-247.

2. Baker, R.R.: Variation of the gas formation regions within a cigarette combustion coal during the smoking cycle; Beitr. Tabakforsch. Int. 11 (1981) 1-17.

3. Summerfield, M., T.J. Ohlemiller, and H.W. Sandusky: A thermophysical mathematical model of steady-draw smoking and predictions of overall cigarette behavior; Combust. Flame 33 (1978) 263-279.

4. Nagao, A, S. Kitao, K. Miura, and M. Horio: Measurement of air flow outside a burning cigarette during a puff using particle image volocimetry; Beitr. Tabakforsch. Int. 21 (2005) 216-222.

5. Yamada, Y.: Cigarette combustion during a puff; CORESTA Smoke and Technology Groups Meeting in Xian, 2001, Abstract Booklet, Abstract No. ST 24, p. 27.

6. Parrish, M.E.: Puff-by-puff and intrapuff analysis of cigarette smoke using infrared spectroscopy; Vibrational Spectroscopy 27 (2001) 29-42.

7. Baker, R.R.: Some burning problems in tobacco science; Proceedings of the international conference on the physical and chemical processes occurring in a burning cigarette, Wake Forest University, WinstonSalem, NC, USA, 1987, pp. 1-61.

8. Loureau, J.M.: CO deliveries: influence of cigarette paper on $\mathrm{CO}$ formation, and CO loss by diffusion and dilution; CORESTA Congress, New Orleans, 2002, Abstract Booklet, Smoke Science and Product Technology, Abstract No. ST 23, p.13.

9. Borgerding, M.F.: What alternative smoking condition(s) does the future hold?; Rec. Adv. Tob. Sci. 23 (1997) 75-151.

10. Sandusky, H., T.J. Ohlemiller, and M. Summerfield: Convective heat transfer measurements in cigarettes; Beitr. Tabakforsch. Int. 9 (1977) 117-125.

11. Bird, R.B., W.E. Steward, and E.N. Lightfoot (Eds.): Transport Phenomena; Wiley International Edition, New York and London, 1960.

12 Torikai, K., S. Yoshida, and H. Takahashi: Effects of temperature, atmosphere and $\mathrm{pH}$ on the generation of smoke components during tobacco pyrolysis; Food Chem. Toxicol. 42 (2002) 1409-1417.

13. Yamamoto, T., U. Anzai, and T. Okada: Effect of cigarette circumference on weight loss during puffs and total delivery of tar and nicotine; Beitr. Tabakforsch. Int. 12 (1984) 259-269. 
14. Waymack, B.E., D.S. Kellogg, D.D. McRae, and R.W. Dwyer: Watts in a cigarette: thermophysical properties of smoldering cigarettes; Tob. Sci. 41 (1997) 74-81.

15. Miura, K., A. Nagao, and K. Uemura: Heat emission from a burning cigarette; Beitr. Tabakforsch. Int. 19 (2001) 245-250.

16. Nagao, A., Y. Yamada, M. Tarora, and K. Miura: Burn rate of cigarette paper during a puff; Tobacco Science Research Conference, Norfolk, USA, 2003, Program Booklet and Abstracts No. 27, pp. 34-35.
Corresponding author:

A. Nagao

Tobacco Science Research Center Japan Tobacco Inc.,

6-2, Umegaoka, Aoba-ku

Yokohama,

Kanagawa 227-8512

Japan

E-mail: atsushi.nagao@ims.jti.co.jp 